\title{
Prehistoric Timber Circles
}

\author{
by Mrs M. E. Cunnington
}

$\mathrm{T}$ HE photographs here reproduced, were taken from the air on 30 June 1926, by Squadron-Leader Insall, v.c., M.C., who was then stationed at Netheravon. The large circular earthwork which appears with a series of concentric dots within its area had always been regarded as a "ring" or "disc" barrow much wasted and defaced as a result of many years cultivation. The ring barrow is a type of pre-historic burial place which occurs comparatively frequently on the Downs of Wiltshire and adjacent counties but is rare elsewhere. It consists of a circular earthen bank with a corresponding ditch, usually on the inner side. The actual burials, apparently invariably after cremation, are usually found in one or more mounds near the centre of the circular area thus enclosed. The banks and ditches are continuous and form unbroken rings; they vary in size from a few yards in diameter up to nearly $200 \mathrm{ft}$. The smaller dark rings shown on the lower part of the photographs near the Amesbury road probably represent the filled-in ditches of barrows that have been destroyed by cultivation.

The earthwork under discussion, in its wasted state, seemed outwardly to have all the characteristics of a very large but otherwise normal ring barrow, i.e., a ditch within a circular bank, and a raised area in the centre. The earthwork lies in a large open arable field, and at the time the photograph was taken the whole area, earthwork and all alike, was covered with a flourishing crop of wheat, already in ear and nearly its full height. The arable field is bounded on the east (right side on the photograph) by the high road from Netheravon and Upavon to Amesbury, it being distant about one and a half miles from the latter village; on the north (upper side of photograph), it is bounded by the new Fargo road to Larkhill camp ; the rectangular light patch adjoining the earthwork is an uncultivated plot used as a stand for ricks ; the light lines running over the earthwork and all across the arable ground are deep plough furrows. To grasp the full significance of the photograph it must be borne in mind that when it was taken the 
PLATE I
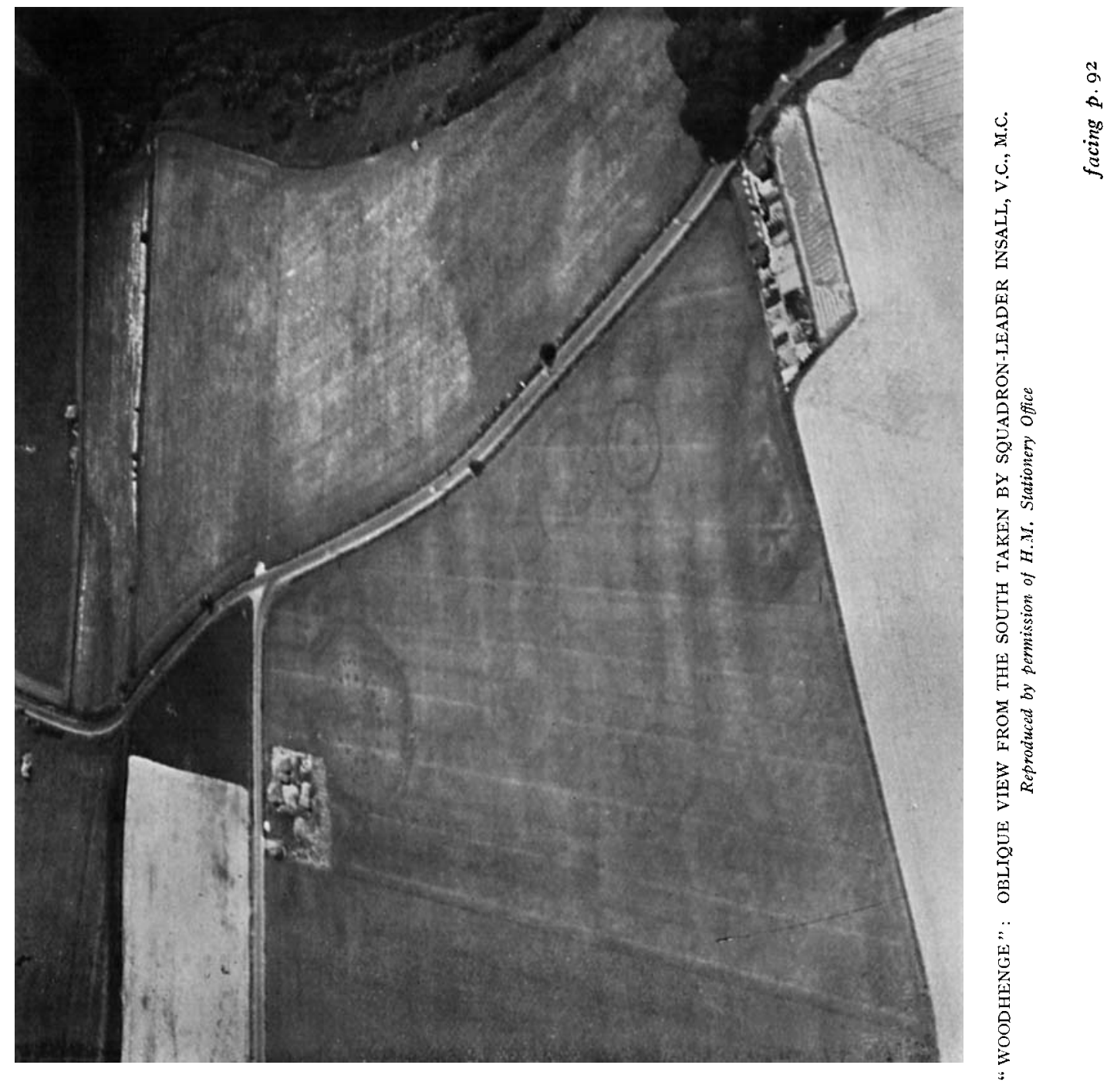


\section{PREHISTORIC TIMBER CIRCLES}

whole area was covered by a tall crop of wheat so that what is seen must be irregularity in colour and growth of the wheat, the actual surface of the ground being hidden. The soil here is only a few inches thick over the chalk, and the long fibrous roots of the wheat penetrate into it with difficulty, if at all. On the other hand, wherever a hole has been previously dug into the chalk the disturbed chalk disintegrates and becomes comparatively soft, and is moreover generally mixed with soil and decayed organic matter, so that the long rootlets penetrate it with ease, and finding congenial conditions the corn grows finer than on the surrounding undisturbed chalk. This is really the secret of many archæological discoveries from the air. Old ditches, pits, and so on, completely filled in and obliterated on the surface, reveal themselves in the growth of crops, creating conditions easily seen with the naked eye but requiring a bird's eye view to follow up.

It was, therefore, realised at once that the dark spots within the earthwork appearing on the photograph in all probability represented pits of some kind, just as the dark ring enclosing them represents actually only the taller and deeper coloured growth of corn over the filled and obliterated ditch, the ditch and bank being themselves quite hidden.

The plan of the circles of holes thus revealed is more or less suggestive of that of Stonehenge, and at once excited great interest among archæologists to whom the photograph was shown by SquadronLeader Insall.

Arrangements were made to test the site by excavation and this was done in August I926; the work was carried on for five weeks when the southern half of the circle was examined, with most interesting results. Presuming that the unexcavated half of the circle agrees with that already done, as the photograph gives every reason to believe, there are six roughly concentric rings of holes surrounded by a ditch immense in proportion to the area enclosed. To test the ditch three sections were cut through it, one each on the east, south, and west sides; in each section it showed the same general features and was found to be unexpectedly large, measuring some $25 \mathrm{ft}$. across the top, from Io $\mathrm{ft}$. to $\mathrm{I}_{4} \mathrm{ft}$. wide at the bottom, and some $7 \mathrm{ft}$. deep. On the photograph there appears to be a break in the continuity of the ditch on the N.E. side towards the Fargo road (on the upper part of the plate); this no doubt represents the entrance to the circle but it has not as yet been proved. The diameter of the earthwork, measured from bank to bank, is approximately $25^{\circ} \mathrm{ft}$. On the outer side of the 


\section{ANTIQUITY}

ditch there are still slight remains of the bank which must once have been proportionate in size to that of the ditch. It must, of course, be understood that the ditch and all the holes were completely filled up and invisible on the surface.

Clear evidence was obtained in excavation that the six concentric rings of holes once held posts or tree trunks varying from I ft. to $3 \mathrm{ft}$. in diameter according to the size of the hole. Plate II, fig. 2 is from a photograph of a model made to scale of the series of holes as excavated; $a, b, c$, represent trial sections cut through the ditch; the position of the entrance at $d$ is approximate only. The holes of the second and third circles appear oblong on plan on account of their ramps, and this brings out how irregularly spaced the holes are. The site was indeed that of an elaborately designed timber construction, possibly comparable in some respects to the more familiar stone circles.

The size and depth and distance between the holes varies in each circle, but in each circle is fairly consistent throughout. In the outermost circle the holes are $6 \mathrm{ft}$. apart from centre to centre, from $\mathrm{I}_{2} \mathrm{ft}$. to $2 \mathrm{ft}$. deep and from $2 \mathrm{ft}$ to $3 \mathrm{ft}$. in diameter. In the second circle the holes were larger and further apart, averaging about $4 \mathrm{ft}$. in depth, and from $3 \frac{1}{2} \mathrm{ft}$. to $4 \mathrm{ft}$. in diameter. The largest of all were those of the third circle, being about $6 \mathrm{ft}$. deep, with a diameter at top of from $4 \mathrm{ft}$. to $5 \mathrm{ft}$. ; the holes of the three inner circles were all much alike, about $3 \frac{1}{2} \mathrm{ft}$. to $3 \mathrm{ft}$. in depth and $2 \mathrm{ft}$. to $3 \mathrm{ft}$. in diameter. It is computed that the outer circle probably consists of 64 holes; the second 32 ; the third, I6; the fourth, 20 ; the fifth, 20 ; and the sixth, 14 holes. In addition to the six circles of post holes there is an inner seventh series of holes of quite different character; they are shallow and very irregularly cut ; whether they really form a seventh circle, and what purpose they served, are both alike at present uncertain.

Two burials were found during the excavations, one, a crouched skeleton of a child, near the centre, and the other a crouched skeleton of an adult in a grave dug below the floor of the ditch in the eastern section.

As a result of excavation it was found that the raised centre of the circle was not due to the remains of a mound but to the fact that the ground had been pared off all round from the centre, towards the edge of the ditch, so that the centre is the natural level of the ground, and only appears raised as a result of the artificial lowering of the surrounding area. 
PLATE II

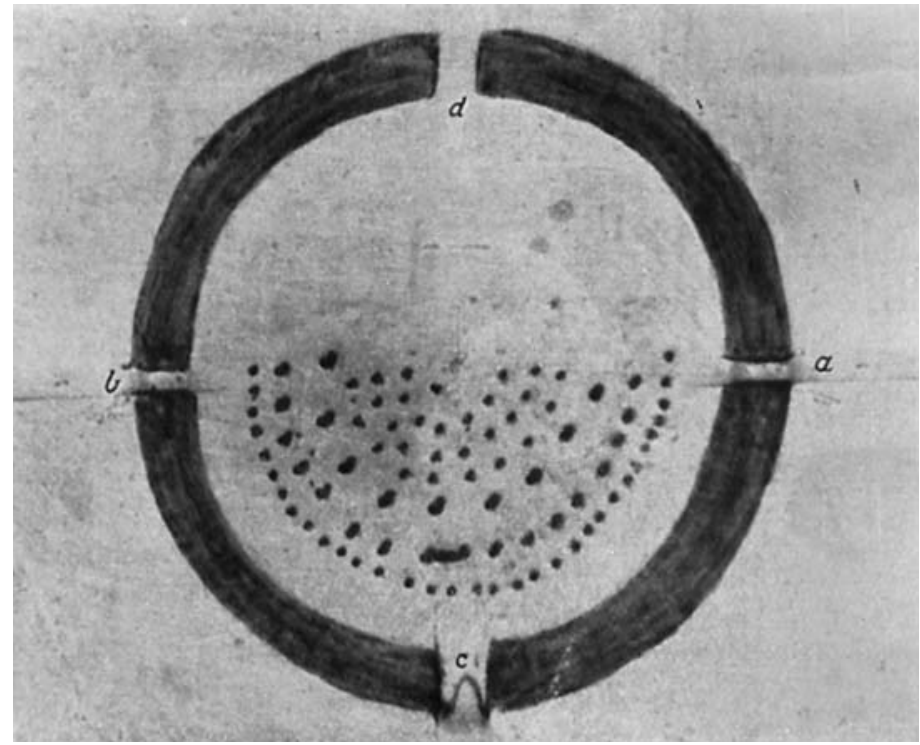

1.- "WOODHENGE": MODEL SHOWING AREA EXCAVATED

DURING 1926. THE LETTERS $a-d$ INDICATE TRENCHES CUT

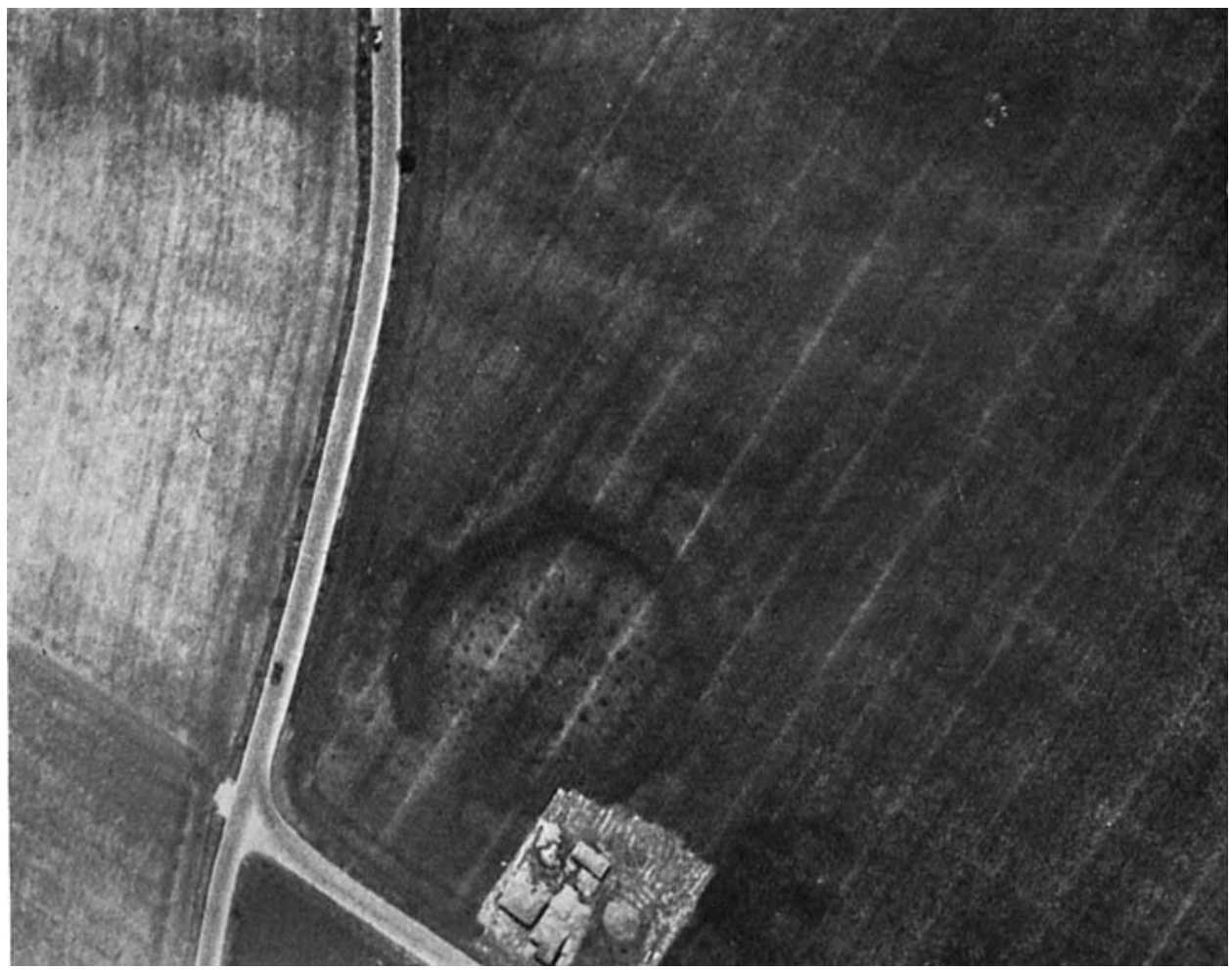

2.-" WOODHENGE": VERTICAL VIEW TAKEN 30 JUNE, 1926, FROM A HEIGHT OF 4900 FELT, BY SQUADROA-LEADER INSALL, V.C., M.C.

Reproduced by permission of H.M. Siationery Office 


\section{PREHISTORIC TIMBER CIRCLES}

The monument is, so far as at present known, unique either in the British Isles or abroad, but probably there are others as yet undiscovered waiting to be revealed by photography from the air or by other means. As it stands at present it is the most sensational archæological discovery made by means of photography from the air, because unlike that of the continuation of the avenue at Stonehenge, it was quite unsuspected and reveals a new type of monument.

As to the purpose for which it was designed, or the date of its construction, it would be premature to speak now, only about one half of the circles having been examined. The objects found have been few, and pottery, which usually affords the most valuable clue for dating purposes, was present only in small fragments. of 1927 .

It is hoped to continue the excavation of the site in the summer 